\title{
ERYTHEMA COMPONENT OF THE TUBERCULIN REACTION
}

\author{
F. O'Grady
}

Department of Bacteriology, St. Bartholomew's Hospital, London, E.C.г.

THE development of erythema is often a striking feature of the reaction to tuberculin. It occurs in the cutaneous test of Von Pirquet, and its development was the criterion of positivity in the conjunctival test of Wolff-Eisner and Calmette. It is usually well developed in the test which superseded both of these, the intracutaneous test of Mantoux. Over the years, however, particularly with the extensive use of the Mantoux test for survey purposes, the significance of the erythema component of the reaction has been seriously questioned. Its development has been largely abandoned as the index of a positive reaction, and the idea has as a result become widespread that the development of erythema is a non-specific response to the irritant effect of tuberculin which is quite unrelated to the presence of true tuberculin sensitivity.

I do not propose to question, or even to discuss, the validity of the criteria at present used for defining a positive tuberculin reaction. I hope, however, to be able to show that erythema is as much a characteristic part of the tuberculin reaction as is induration and that the erythema component exhibits some interesting, and possibly important, properties of its own. The observations are based on testing almost 200 young service men, just over half of whom were suffering from active tuberculosis. They were tested with old tuberculin by conventional techniques beginning with I T.U., followed 48 hours later (if induration of $6 \mathrm{~mm}$. diameter failed to develop) by 10 T.U., and again 48 hours later, if the reaction was negative, by 100 T.U.

The pattern of development of erythema in positive tuberculin reactions can be divided into several groups which are illustrated in Fig. I. The thick lines show the course of induration. The lower edge of the curve shows the average diameter, and the thickness of the line the depth of induration. In the commonest kind of reaction the diameter of induration reaches its maximum around 48 hours and then falls to a slightly smaller value which is often maintained
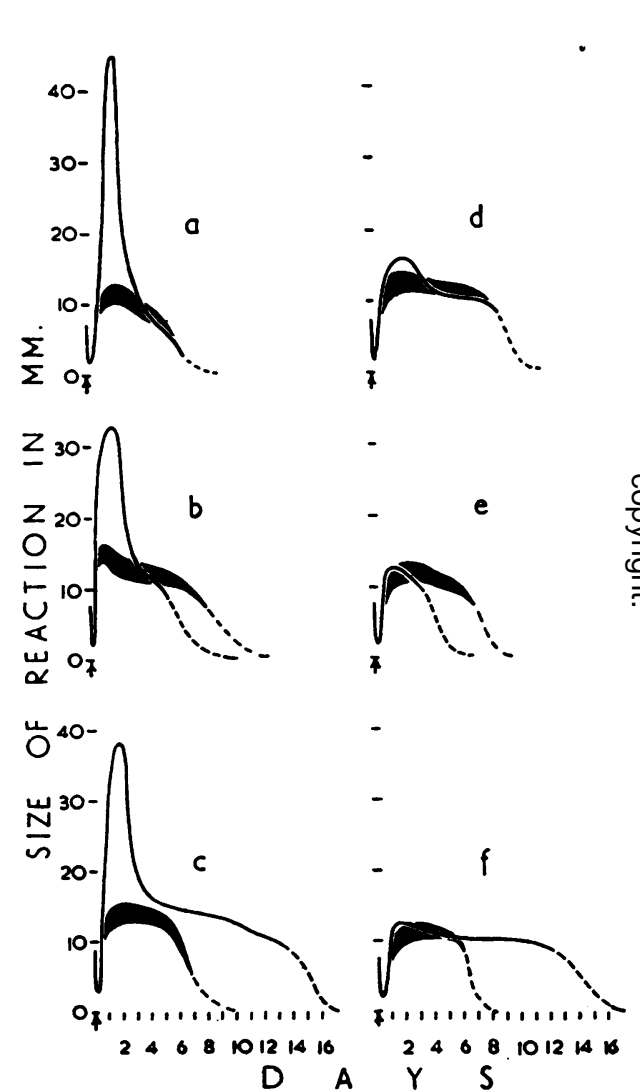

FIG. I.-The thick line indicates induration; the lowe? cdge of the curve shows the diameter, and the thickness of the line the depth of induration. The overlying thin line shows the diameter of erytheman $a, b$ and $c$ : reactions in which maximum erythemas was much greater than induration and lasted $(a)$ same, $(b)$ shorter and $(c)$ longer time than induration $d, e$ and $f$ : reactions of durations corresponding $\omega$ with $a, b$ and $c$, in which little erythema occurre beyond reddening of the indurated plaque.

for some time. The depth of induration also reaches its maximum around 48 hours and then progressively declines so that the indurated plaque disappears by shrinkage in depth rather than $\frac{\mathrm{D}}{\mathrm{D}}$ 
contraction in diameter. In fact, a pigmented area of the size of induration often remains for some considerable time. This disappearance of induration without change in diameter is shown in the figure by the dotted line.

If the erythema component of the reaction is superimposed on induration, two broad groups of reactions can be distinguished: those in which a large area of erythema appears, and those in which there is very little erythema outside the indurated plaque. Within these two groups, illustrated on the left and right of the figure, several sub-group which correspond to each other can be distinguished. In the first, erythema reaches its maximum around 48 hours and then rapidly contracts until only the indurated plaque is red. Induration and erythema ultimately disappear together. In the second type of response, erythema reaches its maximum at about the same time but much more rapidly disappears leaving the indurated plaque pallid. In the final type of response, erythema, having passed its maximum, contracts to about the size of the indurated plaque but then persists for some time after palpable induration has disappeared.

The question arises whether these different responses are all the result of true tuberculin sensitivity, and whether the differences between them have any particular significance. It is possible that the differences depend on dosage, or on intensity of reaction. It is possible that the large reactions are specific and the small nonspecific or, of course, the other way round. It may be that the differences are related to the presence or absence of active tuberculosis, or that they reflect differences in the cutaneous reactivity of different individuals similar to that seen when some patients develop large and some small reactions to histamine or simple skin irritants.

A number of these possibilities can be explored by examining the relationship between erythema and induration in tuberculous and non-tuberculous subjects. Before this can be done, however, there is a difficulty which has to be considered. Not all tuberculous patients develop reactions like those illustrated in Fig. I. In some, a reaction of a different form develops which is illustrated in Fig. 2. Instead of induration developing in the normal way, as illustrated on the left of the figure, induration reaches its maximum at about the normal time but then extremely rapidly disappears so that the easily palpable plaque which is a feature of the normal reactions is, in these tuberculosis patients, extremely short-lived. Samson Wright used to teach that medical discoveries are commonly re-made at 50-year intervals and some time after I had first noticed these attenuated reactions in the presence of active

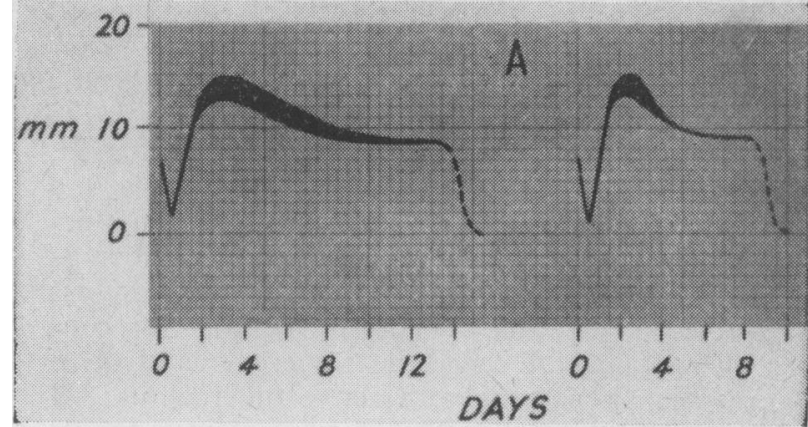

FIG. 2.-Comparison of the 'normal' and 'tuberculous' response. Depth of induration is shown by the thickness of the line and diameter by the lower edge of the curve.

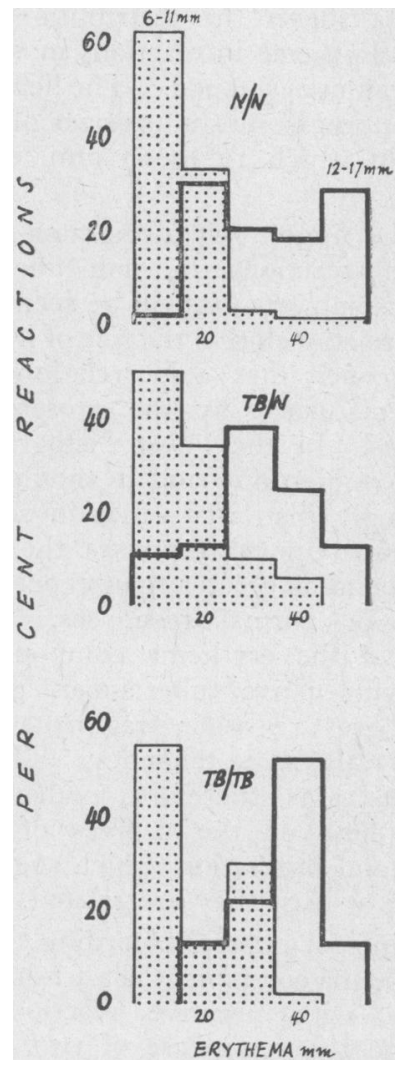

Fig. 3.-Distribution of maximum sizes of erythema in reactions developing 6 to $\mathrm{II}$ $\mathrm{mm}$. or 12 to $17 \mathrm{~mm}$. induration: in non-tuberculous subjects with 'normal' reactions $(\mathrm{N} / \mathrm{N})$; tuberculous subjects with 'normal' reactions (TB/N); and 'tuberculous' reactions (TB/TB). 
tuberculosis (O'Grady, 1956), I found that Wolff-Eisner had described the same phenomena almost exactly 50 years before Wolf-) Eisner and Teichmann, 1908). In looking at the relationship between erythema and induration, therefore, it is necessary to divide the reactions into three groups: the normal kind of reaction developing in non-tuberculous subjects; the normal kind of reaction developing in tuberculous subjects; and the attenuated, or what for convenience may be called the 'tuberculous' type of reaction in patients with active tuberculosis. If the 'tuberculous' reaction occurs in its typical form in normal people it does so extremely rarely, and the fourth possible group: 'tuberculous' reactions in non-tuberculous subjects, may, for the present purposes, be ignored.

In Fig. 3 the relationship between the maximal sizes of erythema and induration is shown. The dotted area shows the distribution of sizes of maximum erythema in reactions in which 6 to $\mathrm{II}$ $\mathrm{mm}$. induration developed. The heavy line shows the distribution of mazimum sizes of erythema in reactions in which 12 to $17 \mathrm{~mm}$. of induration developed.

From the upper two histograms-which refer to normal reactions in non-tuberculous and tuberculous subjects-it will be seen that there is an overall relationship in the size of induration and erythema, and that this relationship is not evidently disturbed by the presence of active tuberculosis. In the lower histogram however, there is a suggestion-and it should not be put more strongly than that-that in some subjects showing 'tuberculous' responses, the size of maximum erythema is greater than expected by com parison with normal responses. This hyperreactivity of the erythema component in some patients with active tuberculosis is of interest because there are other fragments of evidence which show the same tendency. There is in the positive reactions, therefore, evidently some relationship between the degrees of response of erythema and induration which suggests that to this extent at least they are related.

The principal quarrel regarding the specificity of the erythema component has arisen, however, in connection with negative reactions. Negative reactions to tuberculin are of two kinds: those which develop in tuberculin-positive subjects when they are tested with inadequate doses of tuberculin, and those which develop in patients who fail to respond to the largest doses of tuberculin employed. The differences in the behaviour of erythema in these two groups of reactions is instructive, and is shown in Table $I$. The reactions in the two groups-those who ultimately proved positive, and those who ultimately proved
Table 1.-Maximum Erythema in Negative REACTIONS

\begin{tabular}{|c|c|c|c|c|c|c|c|c|}
\hline \multirow{2}{*}{\multicolumn{2}{|c|}{$\begin{array}{c}\text { Maximum } \\
\text { induration } \\
\mathrm{mm} \text {. }\end{array}$}} & & \multicolumn{5}{|c|}{ Maximum erythema $\mathrm{mm}$. } & $\frac{2}{c}$ \\
\hline & & 0 & $1-5$ & $6-10$ & I I - I 5 & $16-20$ & $2 \mathrm{I}-25$ & 26-畓 \\
\hline $\begin{array}{c}\text { Positive } \\
\text { o.. } \\
\text { I-5 }\end{array}$ & $\begin{array}{l}\cdots \\
\cdots\end{array}$ & $\begin{array}{l}78 \\
\text { I I }\end{array}$ & $\begin{array}{r}7 \\
61\end{array}$ & $\begin{array}{l}20 \\
74\end{array}$ & $\begin{array}{l}10 \\
16\end{array}$ & $\begin{array}{l}5 \\
8\end{array}$ & $\begin{array}{l}1 \\
4\end{array}$ & $\frac{\text { 을 }}{\frac{1}{\overline{0}}}$ \\
\hline $\begin{array}{c}\text { Negative } \\
0 . . \\
1-5\end{array}$ & $\begin{array}{l}\cdots \\
\cdots\end{array}$ & $\begin{array}{r}1 \\
1\end{array} \quad 5$ & $\begin{array}{l}2 \\
6\end{array}$ & $\begin{array}{l}2 \\
5\end{array}$ & $\begin{array}{l}3 \\
\mathbf{1}\end{array}$ & I & $\mathbf{I}$ & 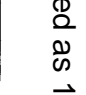 \\
\hline
\end{tabular}

Positive: Relation between maximum erythema and maximum induration in negative reactions to small doses in subjects who ultimately proved positive to larger doses of tuberculin:

Negative: Relation between maximum erythema ary maximum induration in negative reactions subjects negative to roo t.u.

TABLE 2

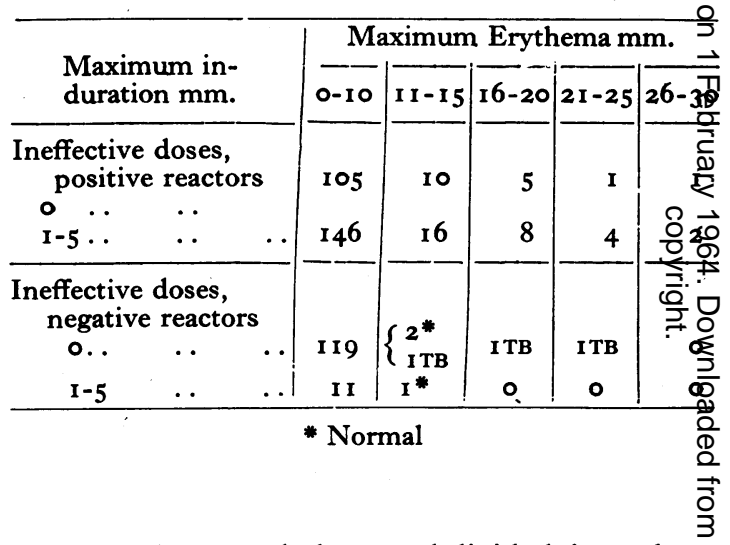

negative-have each been subdivided into those reactions in which no induration developed at a and those in which induration developed but failed to reach $6 \mathrm{~mm}$. in diameter.

It will be seen that large areas of erythema des veloped more frequently in the positive than in the negative patients and that the broad relationshig between erythema and induration was preservea in that erythema occurred more frequently in the presence of induration than in its absence.

Of the 136 patients who developed no indurae. tion, far and away the majority (II5) failed to develop any erythema, and in the group developing some induration, this was regularly associated wit the development of erythema. There are number of reasons for believing that erythema les than $10 \mathrm{~mm}$. in diameter may not be the resulp of true tuberculin sensitivity. It is worthwhile looking in some detail, therefore, at the reactions larger than this size. It will be seen in Table $Z_{2}$ that of the six negative reactors who develope erythema of I I mm. or more, the two developing 
the largest zones (and one other patient who failed to develop induration) were suffering from active tuberculosis. Hence only two non-tuberculous patients amongst 136 negative reactors developed erythema more than $10 \mathrm{~mm}$. in diameter in the absence of induration. This hardly supports the view that the development of erythema in response to tuberculin is entirely non-specific. In some ways more interesting is the development of lone erythema in patients with active tuberculosis. A number of workers have now described the failure of some tuberculous patients to develop conventional positive reactions on testing with large doses of tuberculin, even though no recognized cause of reduced sensitivity could be demonstrated. Amongst those encountered in this series, although induration did not develop, erythema always occurred. I suggest that this reaction represents an extreme form of the tuberculous response in which, while erythema is preserved, induration has become so attenuated as to be unrecognized.

Fig. I and Table $\mathrm{I}$ are taken from Brit. F. Dis. Chest (1959), 53, 181 , and Fig. 2 from Brit. F. Dis. Chest (1956), 50, 159, with permission of the Editor.

\section{REFERENCES}

O'Grady, F. (1956): Mantoux Reaction Patterns in Active and Arrested Tuberculosis, Brit. F. Tuberc., 50, 159. WolfF-Eisner, A., and Teichmann, F. (1908): Die Prognostische Bedeutung der Conjunctivalen und Cutanen Tuberculinreaktion, Berl. klin. Wschr, 45, 65 .

Continued from page 69.

\section{REFERENCES}

KARUSH, F., and EISEN, H. N. (1962): A Theory of Delayed Hypersensitivity, Science, 136, 1032.

KAY, J., and RiEke, W. O. (1963): Tuberculin Hypersensitivity: Studies with Radioactive Antigen and Mononuclear Cells, Science, I39, 487.

Kosunen, T. U., Tinen, W. S., and Waksman, B. H. (r962): Use of Radioautography to Show Cell Proliferation in Delayed Hypersensitivity Reactions, Fed. Proc., 21, 274.

LANDsteiner, K., and Chase, M. W. (I942): Experimental Transfer of Cutaneous Sensitivity to Simple Compounds, Proc. Soc. exp. Biol. (N.Y.), 49, 688 .

McCluskey, R. T., Benacerraf, B., and McCluskey, J. W. (1963): Studies on the Specificity of the Cellular Infiltrate in Delayed Hypersensitivity Reactions, $\mathcal{F}$. Immunol., 90, 466.

Metaxas, M. N., and Metaxas Buhler, M. (1948): Passive Transfer of Local Cutaneous Hypersensitivity to Tuberculin, Proc. Soc. exp. Biol. (N.Y.), 69, 163 .

Najarian, J. S., and Feldman, J. D. (r96r): Passive Transfer of Tuberculin Sensitivity by Tritiated Thymidine Labeled Cells, F. exp. Med., II4, 779 .

Turk, J. L. (1962): The Passive Transfer of Delayed Hypersensitivity in Guinea-pigs by the Transfusion of Isotopicallylabelled Lymphoid Cells, Immunology, 5, 478.

, and OORT, J. (1963): A Histological Study of the Early Stages of the Development of the Tuberculin Reaction After the Passive Transfer of Cells Labelled with $\left({ }^{3} \mathrm{H}\right)$-thymidine, Ibid., 6, 140. 